\title{
Effective Financing of Environmentally Adjusted Multifactor Productivity Growth in Sustainable Development Framework - An International Comparative Study
}

\author{
Viktor Prokop ${ }^{1}$, Jan Stejskal ${ }^{1}$ and Ondrej Kuba ${ }^{1}$
}

\begin{abstract}
Sustainability in innovation activities financing is undoubtedly one of the important requirements that determine the business environment in all developed countries of the world. Different countries apply different innovation models or policies, ways to support or finance their entrepreneurial innovation activities respectively. They significantly shape or cultivate an innovative environment in which different relationships and linkages between actors take place. Therefore, it is necessary to analyze individual determinants, their sustainability, and their efficiency in view of the expected outcomes - environmentally adjusted multifactor productivity growth. We used data from the OECD statistics 2009-2013 for all developed countries in the world. We used DEA (data envelopment analysis) and super-efficiency-DEA method for our international comparative study. Our results show that the developed countries use the combination of private and public financial sources in different way. These are countries that can be perceived as a benchmark - it is therefore possible to compare even partial values of indicators and define public policies for support of selected entrepreneurs. The DEA software also allows you to obtain a numerical benchmark of inputs and outputs for every country. Our finding contributes to the theoretical debate on innovation and eco-innovation models in framework of sustainable development. The results of the analysis confirm the importance of financial sources, human resources and sustainable public sector interventions that influence the environmentally adjusted productivity growth.
\end{abstract}

Keywords: environmentally adjusted productivity growth, sustainable development, financing, OECD

\section{Introduction}

Many scientific studies and reports from international organizations (i.e. OECD, World Bank) have shown that the environment and the economy are interconnected. It is not possible to separate the effort to preserve the quality of the environment for citizens and to independently implement economic measures that have environmental impacts. Obviously, industrial production itself, but also household consumption (as part of the economy of each country), produce or produce a number of negative environmental effects, causing irreversible degradation of the environment, various ecosystems, resulting in depletion of natural resources, faster changes in nature and weather. These in turn affect the quality of individual people life on different continents (Gu, Willox \& Hussain, 2019). This is countered by individual governments applying environmental policies, spending a lot of money and trying to reverse the consequences. It is not easy at all to set public policy objectives to have positive environmental impacts. For example, in the European Union, there is a harmonized approach to environmental policy such as The Europe 2020 Strategy. The European Commission sets out priority or 
priority directions under various measures on environmental issues. These measures are subsequently reflected in the financial frameworks. Promoting environmental innovation is one of the important frameworks. These are so-called eco-innovations, which serve to strengthen the economic growth of enterprises and regions, and at the same time to represent a competitive advantage in international and national markets, whilst also undermining the EU's objectives and priorities in achieving environmental goals and standards (Wysokińska, 2016).

Sustainability is an essential component of environmental policy. Thus, individual economic actors must understand that the common endeavor is to continue to provide the services and goods that consumers need, but it needs to be done to avoid environmental degradation. Economic operators are failing in a clean market precisely in the perception of their needs in the short and long term. Thus, there are market failures, the elimination of which is the task of governments and their politicians (Vandermeersch, 2017).

It is important to realize that the intervention of the state into the market mechanism leads to inefficiency and disbalances. Different kinds of public regulatory and reallocation interventions can affect the production capacity of enterprises, so it is necessary to examine the different components of production functions, incorporate elements of sustainability into them and model economic behavior so as not to reduce the production capacity, absorption capacity of enterprises and at the same time to meet the goals environmental policies.

The remainder of this paper is structured as follows. In the next section, we present the theoretical background for eco-innovations, production function and multifactor productivity growth. Section 3 provides the characteristics of the dataset and the research methodology. Section 4 presents the experimental results. In Section 5, we discuss the results that were obtained and concluded with the paper for suggestions for future research.

\section{Theoretical Background}

Already in studies OECD (e.g. OECD, 2001), it has already shown that traditional approaches to productive function, respectively enterprise productivity measurement does not take into account any environmental and sustainable principles. According to the OECD, this is because income from the use of natural resources is included in the production function as a capital input (direct cost). The resource rents are mostly not taken into account. It follows logically that increased use of natural resources increases production function and thus productivity. Secondly, it is necessary to take into account also long-term investment costs, or expenditures and removal of environmental burdens. Typically, investment costs are included in production functions, while capital output (return, benefit) of these investments is not included. Again, it can be induced that efforts to reduce pollution increase the productivity rate. These findings must also be incorporated into public policies. There politicians may have a misconception about the sources of productivity growth and hence they can misrepresent public policy (specifically objectives and activities). Typical allocation inefficiency is the consequence of this wrong public decision. 
Scholars Brandt et al. (2014) in their studies seeks to modify procedures how to measure the productivity. They defined growth accounting approach to productivity measurement, which helps to better determine the degree of productivity or its flexibility with respect to GDP. Other studies explore the relationship between economy and environment (Stern, 2008 or Stiglitz, Sen \& Fitoussi, 2009). This study demonstrates the link between business (production) and the environment. These studies perceive productivity as the efficiency of transforming inputs into outputs, which is considerably simplified. Therefore, they propose to measure productivity with multifactor productivity, which describes the relationship between outputs (business performance) and input production factors. The multifactor productivity (MFP) will help detect whether factor utilization efficiency helps increase overall productivity or whether technology or quality has improved, which has impacted overall productivity. Gu, Willox \& Hussain (2019) propose to supplement the multifactor productivity by environmental components and estimates of environmentally adjusted multifactor productivity (EAMFP). They supplement the original calculation with the previously unread inputs and outputs described above. They take into account both the environmental dimension and sustainability. They analyzed the Canadian manufacturing sector and have shown that adjusted multifactor productivity is growing more slowly than MFP index. The proposed EAMFP index then corresponds to the logical requirements, i.e. the adjusted multifactor productivity index will grow when reducing environmental damage.

Gu, Willox \& Hussain (2019) have designed a framework for estimating environmentally multifactor productivity in their work under perfect competition assumption as follows:

$\frac{\partial \ln Y}{\partial t}=\frac{P_{L} L}{P_{Y} Y} \frac{\partial \ln L}{\partial t}+\frac{P_{K} K}{P_{Y} Y} \frac{\partial \ln K}{\partial t}+\frac{P_{M} M}{P_{Y} Y} \frac{\partial \ln M}{\partial t}+\frac{\partial \ln M F P}{\partial t}$

where $\mathrm{L}$ is labour, $\mathrm{K}$ capital, $\mathrm{M}$ intermediate inputs, $\mathrm{P}_{\mathrm{L}}$ wage rate, $\mathrm{P}_{\mathrm{K}}$ rental rate, $\mathrm{P}_{\mathrm{Y}}$ price of desirable output, $\mathrm{P}_{\mathrm{M}}$ price of intermediate inputs.

After adjusting (described in detail in their study) it is possible to write the equation environmentally adjusted multifactor productivity as follows:

$\frac{\partial \ln E A M F P}{\partial t}=\frac{P_{Y} Y}{P_{Y} Y+P_{R} R} \frac{\partial \ln Y}{\partial t}+\frac{P_{R} R}{P_{Y} Y+P_{R} R} \frac{\partial \ln R}{\partial t}-\frac{\partial \ln Z}{\partial t}$

where $P_{R}$ is the price of an individual undesirable output to be estimated and $R$ is the observed quantity of undesirable output measured in tonnes. The derivative of $\ln Z$ then contains the variables $\mathrm{L}, \mathrm{K}, \mathrm{M})$.

From the above equations, it is clear that the multifactor production function must contain all the production factors entering to the production, and further variables related to the elimination of environmental damage. Very detailed data inputs are needed to calculate EAMFP and this productivity can be determined in microeconomic and also macroeconomic assumptions. This will allow assessing and comparing the effectiveness of implemented public policies.

There are other approaches to macroeconomic assessment of productivity. For example, Égert (2016) uses multi-factor productivity in his study. Its approach does not take environmental aspects into account, but rather addresses determinants such as foreign direct investment or regulatory measures by the public sector. The macroeconomic study was conducted by Rodríguez, Haščič \& Souchier (2018), using the approaches described above, including modified EAMFP index. They used the OECD and G20 data and 
found that growth in OECD countries was created almost exclusively through productivity growth. The results also point to a shift towards more environmentally friendly production processes in many countries. In fact, most OECD countries have reduced their emissions over the past two decades, and these pollution abatement efforts have led to an upward adjustment in GDP growth rates, allowing an accurate assessment of their economic performance. Other studies that work at the macroeconomic level have analysed the situation in OECD countries is missing. This gives room for defining the goal of our paper. Therefore, we aim to identify OECD countries that have achieved environmentally adjusted multifactor productivity growth between 2009-2010 and 20122013 and to analyse which of these countries efficiently used human sources in R\&D and public/private $\mathrm{R} \& \mathrm{D}$ spending to reach this growth. Moreover, we aim to propose benchmarks for less and non-efficient countries and some practical implications for policy makers.

\section{Data and Methodology}

The data used in this study were obtained from OECD databases while we are focusing only on the selected OECD countries that have achieved environmentally adjusted multifactor productivity growth between 2009-2010 and 2012-2013 (when selecting countries, the availability of the data had to be taken into account). These countries are Austria, Belgium, Canada, Czech Republic, Denmark, Estonia, France, Germany, Israel, Korea, Luxembourg, Sweden, United Kingdom, and United States. In this study, we are using 1-year time delay between inputs (2009 and 2012) and outputs (2010 and 2013)1. Based on the previous mentioned studies, as output variable, the environmentally adjusted multifactor productivity growth measured (in \%) is used. As inputs, to analyse countries efficiently in using human sources in $R \& D$ and public/private R\&D spending, following variables were used:

- R\&D personnel - RDPER (per thousand labour force) that are commonly expected as a key to higher productivity (Zhang et al., 2003);

- Business enterprise expenditure on R\&D - BERD (in \% of GDP) because private sector innovation and $\mathrm{R} \& \mathrm{D}$ activities and expenditures substantially contribute to sustainable productivity and growth (Hud \& Hussinger, 2015);

- Government expenditure on R\&D - GOVERD (in \% of GDP) that support firms' innovation and cooperation that could lead to other positive effects influencing countries productivity (Hu \& Yongxu, 2019).

In research, also the control variable was engaged. It is environmentally related tax revenue - ERTAX (in \% of GDP) because the stringency of environmental taxes is seen as relevant driver of firms' as well as countries' innovation and productivity (see e.g. Franco \& Marin, 2017).

Two modeling approaches have been used in this cross-country analysis. We are using Data Envelopment Analysis (DEA) that was widely used in measuring energy and environment efficiency at a macro-economic level (Yang et al., 2015) and super-

${ }^{1}$ Griliches (1998) empirically proved that there is no time delay with significant impact on the results of analyses. 
efficiency DEA (SEDEA). Combination of these two models is commonly used (e.g. Du et al., 2010; Guo et al., 2017). DEA is an analytical tool that is suitable for efficiency evaluation, evaluation of production capability and performance in an economic entity (input and output units are analyzed). This method assumes homogeneous units, in our study OECD countries are these units (due to the space limitation, here we generally describe selected models, to see more e.g. Halaskova et al., 2018; Prokop et al., 2018). DEA works on a well-known principle - evaluates the efficiency of input-to-output conversion, measures the effectiveness of this conversion. It assumes that all other decision-making units (DMUs) cannot be greater than 1 (100\%). Some scholars describe that the advantage of DEA analysis is the benchmarking indicators provision. These can be used to update public policy, changing the strategy of the evaluated unit to increase efficiency respectively. Therefore, we are using DEA models to propose these improvements. On the other hand, when multiple DMUs are involved, the traditional DEA models present difficulty in ranking the DMUs and thus make further analysis unavailable. Efficient countries reach the rate of effectiveness 1,000 however, we cannot find out which effective country has achieved the best results. In order to overcome this, to remedy the shortage of these models and evaluate DMUs' efficiencies effectively and realistically, Andersen \& Petersen (1993) proposed a super-efficiency DEA. SEDEA can further distinguish efficiency among DMUs and then sort the relative efficiency of these DMUs (Yang et al., 2015). The SEDEA method can further compare the efficient DMUs whose efficiency scores are all 1,000 in the traditional DEA models because provides an efficiency rating of efficient units similar to the rating of inefficient units in DEA models (Chen et al., 2017). Therefore, efficient countries could be subsequently compared according the rate of efficiency they reached (the highest value indicates the most effective country - see below).

Both models of presented research are based on the assumption of variable returns to scale (VRS). The VRS models work with assumptions assuming different types of revenues (increasing, constant or decreasing; Hudec \& Prochadzkova, 2013). VRS model with variable return scale was used for research presented in this paper.

As a possible limitation of these models is that, the SEDEA models under the condition of variable returns to scales may suffer from infeasibility (Fang et al., 2013). Chen (2005) states that no attempt has been made to solve the infeasibility problem, partly because the meaning of super-efficiency has different interpretations. Therefore, in this study, the countries suffering infeasibility were excluded.

\section{Results and Discussion}

To identify the efficient DMUs, first SEDEA model were applied (see Tab. 1 efficient countries reached the rate of effectiveness 1.000 and higher while the larger value indicates a more efficient country) then, to find proposed improvements how to change inputs and outputs to become (more) efficient, DEA models were applied (See Tab. 2). 
Table 1: Results of SEDEA models

\begin{tabular}{|l|c|c|}
\hline \multirow{2}{*}{ Country } & \multicolumn{2}{|c|}{ Input-Oriented VRS Super-Efficiency } \\
\cline { 2 - 3 } & $\mathbf{2 0 0 9 - 2 0 1 0}$ & $\mathbf{2 0 1 2 - 2 0 1 3}$ \\
\hline Austria & 0.729 & 0.721 \\
\hline Belgium & 0.808 & 0.725 \\
\hline Canada & $\mathbf{1 . 2 0 5}$ & $\mathbf{1 . 2 4 0}$ \\
\hline Czech Republic & 0.731 & 0.675 \\
\hline Denmark & $\mathbf{1 . 2 3 6}$ & 0.886 \\
\hline Estonia & 0.810 & 0.832 \\
\hline France & 0.669 & 0.654 \\
\hline Germany & 0.635 & 0.631 \\
\hline Israel & $\mathbf{1 . 0 7 0}$ & 0.634 \\
\hline Korea & 0.648 & 0.806 \\
\hline Luxembourg & 0.682 & 0.663 \\
\hline Sweden & 0.761 & 0.683 \\
\hline United Kingdom & 0.827 & 0.942 \\
\hline United States & $\mathbf{1 . 6 2 2}$ & $\mathbf{1 . 5 8 6}$ \\
\hline
\end{tabular}

Results in Table 1 show that only 4 out of 14 (29\%) OECD countries that reached environmentally adjusted multifactor productivity growth effectively used human sources in $\mathrm{R} \& \mathrm{D}$ and public/private $\mathrm{R} \& \mathrm{D}$ spending between the years 2009-2010. These countries are (according to their efficiency rates) United States (1.622), Denmark (1.236), Canada (1.205), and Israel (1.070). Germany was evaluated as inefficient in comparison with these countries. These results make it difficult to define the causes. For further research, it is necessary to analyse the changes in detail, to focus on the fundamental determinants of productivity growth and analyse what changes in the economies of these countries have occurred. It can be assumed that these countries have a strong focus on the knowledge economy, the use of new technologies in production and the increase in the share of creative industries.

Surprisingly, a decrease in the effectiveness occurred between periods 2009-2010 and 2012-2013. Between the years 2012-2013, only 2 out of 14 (14\%) selected OECD were efficient (United States and Canada). In total, 10 out of $14(71 \%)$ countries reached lower rate of efficiency in comparison with period 2009-2010. On the other hand, Canada, Estonia, Korea, and Great Britain improved their efficiency rates. Here again, it is needed to analyse the reasons. This may be, for example, a fading global economic recession or a lower economic resilience to turbulent changes of some economies.

Table 2 gives both original values and adjusted values that show how the input variables should have been reduced/increased in years 2009 and 2012 so that inefficient countries could reach the efficient frontier and become efficient ${ }^{2}$. For the most of inefficient countries, the presented models suggested reducing expenditures (public/private) on research and development. These results show that there is a need to focus on both categories of R\&D expenditures to avoid increasing inefficiency. For example, private investments in R\&D are generally associated with creation of new products and growing

2 Note that input-oriented models propose changes focusing primarily on input variables or even minor changes on the output side and therefore we show proposed changes on the input side. 
profits. Moreover, Lee \& Min (2015) state that eco-innovations are strongly related to firms' investment in research and development. However, these expenditures must be implemented within the sufficient innovation environments to enable their effective use and the emergence of innovations and environmental innovations as well as environmentally adjusted multifactor productivity growth. It also could lead to creation of additional effects (e.g. spillover effects ${ }^{3}$ ). On the other hand, Lee \& Wu (2016) showed that increased R\&D expenditures could also have negative effects, e.g. for low- tech firms in Taiwan. These inefficiencies also occur within OECD countries. For example, Khoshnevis \& Teirlinck (2018) showed that R\&D active firms suffer from technical inefficiency in Belgium. In the case of public expenditures, Xiaoxu et al. (2018) state that governmental expenditures have an inductive effect on corporate R\&D expenditures at macro level but at micro level the unified research paradigm has not yet formed. Public innovation policies could therefore generate innovation incentives for enterprises as well as they could have crowding-out effect on firms' investments. However, Costantini et al. (2015) state there is a growing consensus on the potential pivotal role played by environmental and innovation public policies in promoting economic development while protecting the environment in OECD countries.

Table 2: Modified changes of inputs in 2009 and 2012

\begin{tabular}{|l|c|c|c|c|c|c|c|c|}
\hline \multirow{2}{*}{ Country } & \multicolumn{2}{|c|}{ RDPER } & \multicolumn{2}{c|}{ BERD } & \multicolumn{2}{c|}{ GOVERD } & \multicolumn{2}{c|}{ ERTAX } \\
\cline { 2 - 9 } & Orig. & Adjust. & Orig. & Adjust. & Orig. & Adjust. & Orig. & Adjust. \\
\hline \multirow{2}{*}{ Austria } & 15.16 & 10.94 & 2.05 & 1.29 & 0.13 & 0.10 & 2.88 & 2.07 \\
& $(13.42)$ & $(9.45)$ & $(1.77)$ & $(1.09)$ & $(0.14)$ & $(0.10)$ & $(2.86)$ & $(2.08)$ \\
\hline \multirow{2}{*}{ Belgium } & 13.69 & 9.93 & 1.59 & 0.80 & 0.19 & 0.14 & 2.15 & 1.56 \\
& $(12.45)$ & $(10.06)$ & $(1.31)$ & $(0.90)$ & $(0.18)$ & $(0.15)$ & $(2.18)$ & $(1.76)$ \\
\hline \multirow{2}{*}{ Canada } & 12.25 & 12.25 & 0.92 & 0.92 & 0.15 & 0.15 & 1.13 & 1.13 \\
& $(12.93)$ & $(12.93)$ & $(1.02)$ & $(1.02)$ & $(0.20)$ & $(0.20)$ & $(1.18)$ & $(1.18)$ \\
\hline \multirow{2}{*}{ Czech Republic } & 11.48 & 7.75 & 0.94 & 0.45 & 0.34 & 0.20 & 2.34 & 1.58 \\
& $(9.64)$ & $(7.05)$ & $(0.72)$ & $(0.52)$ & $(0.31)$ & $(0.23)$ & $(2.42)$ & $(1.77)$ \\
\hline \multirow{2}{*}{ Denmark } & 19.68 & 12.79 & 1.95 & 1.73 & 0.07 & 0.06 & 4.04 & 2.02 \\
& $(18.80)$ & $(18.80)$ & $(2.13)$ & $(2.13)$ & $(0.06)$ & $(0.06)$ & $(4.08)$ & $(4.08)$ \\
\hline \multirow{2}{*}{ Estonia } & 8.52 & 7.09 & 1.22 & 0.38 & 0.20 & 0.16 & 2.74 & 2.28 \\
& $(7.88)$ & $(6.26)$ & $(0.62)$ & $(0.51)$ & $(0.15)$ & $(0.12)$ & $(2.96)$ & $(2.40)$ \\
\hline \multirow{2}{*}{ France } & 14.10 & 9.22 & 1.44 & 0.66 & 0.29 & 0.19 & 2.15 & 1.41 \\
& $(13.61)$ & $(9.11)$ & $(1.36)$ & $(0.91)$ & $(0.36)$ & $(0.24)$ & $(2.14)$ & $(1.43)$ \\
\hline \multirow{2}{*}{ Germany } & 14.31 & 9.04 & 1.95 & 0.84 & 0.41 & 0.23 & 2.12 & 1.34 \\
& $(12.83)$ & $(8.16)$ & $(1.84)$ & $(1.07)$ & $(0.40)$ & $(0.26)$ & $(2.27)$ & $(1.44)$ \\
\hline \multirow{2}{*}{ Israel } & 21.38 & 13.58 & 3.50 & 1.90 & 0.08 & 0.05 & 2.99 & 1.90 \\
& $(9.83)$ & $(9.83)$ & $(3.45)$ & $(3.45)$ & $(0.08)$ & $(0.08)$ & $(3.01)$ & $(3.01)$ \\
\hline \multirow{2}{*}{ Korea } & 15.53 & 6.60 & 3.14 & 0.21 & 0.45 & 0.18 & 2.61 & 2.10 \\
& $(12.67)$ & $(8.21)$ & $(2.45)$ & $(0.95)$ & $(0.43)$ & $(0.24)$ & $(2.34)$ & $(1.52)$ \\
\hline \multirow{2}{*}{ Luxembourg } & 12.04 & 7.75 & 0.70 & 0.45 & 0.35 & 0.19 & 2.38 & 1.58 \\
& $(13.08)$ & $(8.92)$ & $(1.27)$ & $(0.54)$ & $(0.27)$ & $(0.18)$ & $(2.52)$ & $(1.72)$ \\
\hline
\end{tabular}

3 Ghisetti \& Pontoni (2015) state that environmental innovations are a special type of innovations because of their double externality nature. First externality leads to reduction of negative environmental externalities. These externalities arising from knowledge spillovers that could lead to additional investments for its adoption (second externality). 


\begin{tabular}{|l|c|c|c|c|c|c|c|c|}
\hline \multirow{2}{*}{ Country } & \multicolumn{2}{|c|}{ RDPER } & \multicolumn{2}{c|}{ BERD } & \multicolumn{2}{c|}{ GOVERD } & \multicolumn{2}{c|}{ ERTAX } \\
\cline { 2 - 9 } & Orig. & Adjust. & Orig. & Adjust. & Orig. & Adjust. & Orig. & Adjust. \\
\hline \multirow{2}{*}{ Sweden } & 16.06 & 10.97 & 2.22 & 1.17 & 0.16 & 0.11 & 2.40 & 1.64 \\
& $(15.77)$ & $(9.40)$ & $(2.44)$ & $(0.99)$ & $(0.15)$ & $(0.11)$ & $(2.68)$ & $(2.04)$ \\
\hline \multirow{2}{*}{ United Kingdom } & 11.10 & 9.36 & 1.01 & 0.95 & 0.13 & 0.12 & 2.47 & 2.33 \\
& $(11.06)$ & $(8.88)$ & $(1.02)$ & $(0.84)$ & $(0.15)$ & $(0.13)$ & $(2.41)$ & $(1.99)$ \\
\hline \multirow{2}{*}{ United States } & 12.36 & 12.36 & 1.87 & 1.87 & 0.33 & 0.33 & 0.73 & 0.73 \\
& $(10.83)$ & $(10.83)$ & $(1.95)$ & $(1.95)$ & $(0.34)$ & $(0.34)$ & $(0.74)$ & $(0.74)$ \\
\hline
\end{tabular}

Note: Orig. $=$ the original values entered into the analysis, Adjust. $=$ adjusted values that are proposed by DEA analysis and should be perceived as the target in the context of maximum efficiency. Values in brackets belong to the year 2009.

Similarly, to proposed reductions of public and private R\&D expenditures for the most of inefficient countries, the DEA models also suggested reducing in R\&D personnel. However, knowledge and human capital represent key sources of competitive advantage and economic growth in the current rapidly changing knowledge economy (Prokop et al., 2017). Therefore, the firms' actions related to training, information and dissemination in order to improve the absorptive capacity of human resources are seen to be crucial, specifically to encourage and stimulate the development of eco-innovations (MondéjarJiménez et al., 2013; Díaz-García et al., 2015). In this case, training employees in environmental initiatives, creating eco-innovative collaboration networks, and adopting environmental management systems prove to be important changes (as opposed to reducing human resources) that could help to increase countries' efficiency (Huang et al., 2016).

\section{Conclusions}

Many studies have shown that changes in the economic and social environment are accelerating greatly throughout the world. This is mainly due to increased demand for goods and services, as well as significant development of production technologies and information and communication technologies. They enable production to accelerate and become cheaper. However, there is an unfortunate consequence of greater damage to the environment and greater instability in individual countries due to global threats. Therefore, it is necessary to address the role of the state (public sector) in achieving higher economic growth and sustainable development and to emphasize the need for environmental quality.

The aim of the paper was to identify OECD countries whose productivity is also achieved by taking into account environmental factors. We also focused on the changes between selected time periods, which were caused by the different use of human sources in $\mathrm{R} \& \mathrm{D}$ and funding methods.

The results of our analyse show the importance of the business environment, which must be designed to support entrepreneurs and other economic entities. This environment should be called environmentally friendly eco-systems. The system also includes public interventions in the form of applied public policy or financial frameworks to help implement some environmental measures in practice (Ghisetti \& Pontoni, 2015). In their study, these scholars recommend focusing on the quality and 
effectiveness of policy interventions, science and research, and the quality of human resources. Prokop, Stejskal \& Hudec (2019) stated that the funds from private and public sources for the environmentally friendly eco-systems increasing must be allocated effectively. These scholars recommended that the aim of the expenses must increase the absorption capacity of firms (by increasing efficiency in use of workers' knowledge and skills).

Ghisetti \& Pontoni (2015) concluded that eco-innovation is connected within the "policy push/pull effect". These kinds of innovations are coupled with policies that support them (policy-driven) or evoke their need (supply-pushed) or demand (demand-pulled; Cleff and Rennings, 1999, Rennings and Rammer, 2009). The application of this approach can be demonstrated on biofuels. Costantini et al. (2015) demonstrated the existence of a demand-pull approach in practice and complemented a new approach called "technology-push". They highlighted the importance of other determinants of the entrepreneurial ecosystem and the role of the firm in it. Lee \& Min (2015) found that if firms adopt a proactive environmental strategy and manage their business processes, create a competitive advantage, they will gain a unique environment for innovation or to increase their own productivity. Similarly to the other studies for example Melnyk et al., 2003, Porter \& van der Linde, 1995, Sambasivan et al., 2013, for the firms' environmental impact to be neutral, it is necessary to reorient (at least partly) to ecoinnovation. Therefore, firms need to invest in new environmental technologies that reduce emissions and emissions. The introduction of eco-innovation can enable the firm to restructure processes, identify weaknesses or inefficiencies in the production of existing products. All this can help to increase the productivity.

For future research, we need to find out what other factors influence adjusted multifactor productivity growth, depending on the type of industries and economy development. It can be assumed that the degree of development and public policy focus on environmental issues will significantly determine the efficiency of production capabilities and functions.

\section{Acknowledgement}

This paper was supported by the Student Grant Competition (grant no. 18) of University of Pardubice in 2019.

\section{References}

Andersen, P., \& Petersen, N. C. (1993). A procedure for ranking efficient units in data envelopment analysis. Management science, 39(10), 1261-1264.

Brandt, N., P. Schreyer, \& Zipperer, V. (2014). Productivity Measurement with Natural Capital and Bad Outputs. OECD Economics Department Working Papers, no. 1154. Paris: OECD Publishing.

Chen, N., Xu, L., \& Chen, Z. (2017). Environmental efficiency analysis of the Yangtze River Economic Zone using super efficiency data envelopment analysis (SEDEA) and tobit models. Energy, 134, 659-671.

Chen, Y. (2005). Measuring super-efficiency in DEA in the presence of infeasibility. European Journal of Operational Research, 161(2), 545-551.

Costantini, V., Crespi, F., Martini, C., \& Pennacchio, L. (2015). Demand-pull and technology-push public support for eco-innovation: The case of the biofuels sector. Research Policy, 44(3), 577-595. 
Díaz-García, C., González-Moreno, Á., \& Sáez-Martínez, F. J. (2015). Eco-innovation: insights from a literature review. Innovation, 17(1), 6-23.

Du, J., Liang, L., \& Zhu, J. (2010). A slacks-based measure of super-efficiency in data envelopment analysis: a comment. European Journal of Operational Research, 204(3), 694-697.

Égert, B. (2016). Regulation, institutions, and productivity: new macroeconomic evidence from OECD countries. American Economic Review, 106(5), 109-13.

Fang, H. H., Lee, H. S., Hwang, S. N., \& Chung, C. C. (2013). A slacks-based measure of super-efficiency in data envelopment analysis: An alternative approach. Omega, 41(4), 731-734.

Franco, C., \& Marin, G. (2017). The effect of within-sector, upstream and downstream environmental taxes on innovation and productivity. Environmental and resource economics, 66(2), 261-291.

Ghisetti, C., \& Pontoni, F. (2015). Investigating policy and R\&D effects on environmental innovation: A meta-analysis. Ecological Economics, 118, 57-66.

Griliches, Z. (1998). Patent statistics as economic indicators: a survey (pp. 287-343). In R\&D and productivity: the econometric evidence, Chicago: University of Chicago Press.

Gu, W., Willox, M., \& Hussain, J. (2019). Environmentally Adjusted Multifactor Productivity Growth for the Canadian Manufacturing Sector. Statistics Canada, Analytical Studies Branch.

Guo, I. L., Lee, H. S., \& Lee, D. (2017). An integrated model for slack-based measure of super-efficiency in additive DEA. Omega, 67, 160-167.

Halaskova, M., Halaskova, R., \& Prokop, V. (2018). Evaluation of efficiency in selected areas of public services in European Union countries. Sustainability, 10(12), 4592.

http://ec.europa.eu/eurostat/documents/118025/118123/Fitoussi+Commission+report

Hu, A. G., \& Yongxu, D. (2019). Does government R\&D stimulate or crowd out firm R\&D spending? Evidence from Chinese manufacturing industries. Economics of Transition and Institutional Change, 27(2), 497-518.

Huang, X. X., Hu, Z. P., Liu, C. S., Yu, D. J., \& Yu, L. F. (2016). The relationships between regulatory and customer pressure, green organizational responses, and green innovation performance. Journal of Cleaner Production, 112, 3423-3433.

Hud, M., \& Hussinger, K. (2015). The impact of R\&D subsidies during the crisis. Research policy, 44(10), 1844-1855.

Hudec, O., \& Prochadzkova, M. (2013). The relative efficiency of knowledge innovation processes in EU countries. Studies in Regional Science, 43(1), 145-162.

Khoshnevis, P., \& Teirlinck, P. (2018). Performance evaluation of R\&D active firms. Socio-Economic Planning Sciences, 61, 16-28.

Lee, C. L., \& Wu, H. C. (2016). How do slack resources affect the relationship between R\&D expenditures and firm performance?. R\&D Management, 46(S3), 958-978.

Lee, K. H., \& Min, B. (2015). Green R\&D for eco-innovation and its impact on carbon emissions and firm performance. Journal of Cleaner Production, 108, 534-542.

Melnyk, S. A., Sroufe, R. P., \& Calantone, R. (2003). Assessing the impact of environmental management systems on corporate and environmental performance. Journal of operations management, 21(3), 329351.

Mondéjar-Jiménez, J., Vargas-Vargas, M., Segarra-Oña, M., \& Peiró-Signes, A. (2013). Categorizing variables affecting the proactive environmental orientation of firms. International Journal of Environmental Research, 7(2), 495-500.

OECD. Publishing. (2001). Measuring productivity-OECD Manual: Measurement of Aggregate and Industry-Level Productivity Growth. Organisation for Economic Co-operation and Development.

Porter, M. E., \& Van der Linde, C. (1995). Toward a new conception of the environment-competitiveness relationship. Journal of economic perspectives, 9(4), 97-118.

Prokop, V., Stejskal, J., \& Hajek, P. (2018). Effectiveness of Selected Knowledge-Based Determinants in Macroeconomics Development of EU 28 Economies. In Finance \& Economics Readings. Springer, Singapore, 69-83.

Prokop, V., Stejskal, J., \& Hudec, O. (2019). Collaboration for innovation in small CEE countries. E+ M Ekonomie a Management, 22(1), 130-144.

Prokop, V., Stejskal, J., \& Kuvíková, H. (2017). The Different Drivers of Innovation Activities in European Countries: A Comparative Study of Czech, Slovak, and Hungarian Manufacturing Firms 1. Ekonomicky casopis, 65(1), 31. 
Rodríguez, M. C., Haščič, I., \& Souchier, M. (2018). Environmentally Adjusted Multifactor Productivity: Methodology and Empirical Results for OECD and G20 Countries. Ecological Economics, 153, 147160.

Sambasivan, M., Bah, S. M., \& Jo-Ann, H. (2013). Making the case for operating "Green": impact of environmental proactivity on multiple performance outcomes of Malaysian firms. Journal of cleaner production, 42, 69-82.

Stern, N. (2008). The economics of climate change. American Economic Review, 98(2), 1-37.

Stiglitz, J. E., Sen, A., \& Fitoussi, J. P. (2017). Report by the commission on the measurement of economic performance and social progress. Available at:

Vandermeersch, D. (2017). The single European act and the environmental policy of the European Economic Community. In European Environmental Law. London: Routledge, 79-101.

Wysokińska, Z. (2016). The "new" environmental policy of the European Union: A path to development of a circular economy and mitigation of the negative effects of climate change. Comparative Economic Research, 19(2), 57-73.

Xiaoxu, K., He, Z., \& Yang, Y. (2018). Government Subsidy, Research and Development Expenditure and Independent Innovation of Enterprise. In 4th International Conference on Economics, Management, Law and Education (EMLE 2018). Atlantis Press.

Yang, L., Ouyang, H., Fang, K., Ye, L., \& Zhang, J. (2015). Evaluation of regional environmental efficiencies in China based on super-efficiency-DEA. Ecological Indicators, 51, 13-19.

Zhang, A., Zhang, Y., \& Zhao, R. (2003). A study of the R\&D efficiency and productivity of Chinese firms. Journal of Comparative Economics, 31(3), 444-464. 